\title{
Predicting approximate seismic responses in multistory buildings from real-time earthquake source information, for earthquake early warning applications
}

\author{
Gemma Cremen $^{1}$ (D) $\cdot$ Omar Velazquez ${ }^{2} \cdot$ Benazir Orihuela $^{3} \cdot$ Carmine Galasso $^{4,5}$
}

Received: 19 December 2020 / Accepted: 25 March 2021 / Published online: 15 June 2021

(c) The Author(s) 2021

\begin{abstract}
Regional earthquake early warning (EEW) alerts and related risk-mitigation actions are often triggered when the expected value of a ground-motion intensity measure (IM), computed from real-time magnitude and source location estimates, exceeds a predefined critical IM threshold. However, the shaking experienced in mid- to high-rise buildings may be significantly different from that on the ground, which could lead to sub-optimal decisionmaking (i.e., increased occurrences of false and missed EEW alarms) with the aforementioned strategy. This study facilitates an important advancement in EEW decision-support, by developing empirical models that directly relate earthquake source parameters to resulting approximate responses in multistory buildings. The proposed models can leverage real-time earthquake information provided by a regional EEW system, to provide rapid predictions of structure-specific engineering demand parameters that can be used to more accurately determine whether or not an alert is triggered. We use a simplified continuum building model consisting of a flexural/shear beam combination and vary its parameters to capture a wide range of deformation modes in different building types. We analyse the approximate responses for the building model variations, using Italian accelerometric data and corresponding source parameter information from 54 earthquakes. The resulting empirical prediction equations are incorporated in a real-time Bayesian framework that can be used for building-specific EEW applications, such as (1) early warning of floor-shaking sensed by occupants; and (2) elevator control. Finally, we demonstrate the improvement in EEW alert accuracy that can be achieved using the proposed models.
\end{abstract}

Keywords Earthquake early warning $\cdot$ Real-time seismic response prediction $\cdot$ Decisionmaking under uncertainty

Gemma Cremen

g.cremen@ucl.ac.uk

Extended author information available on the last page of the article 


\section{Introduction}

Earthquake early warning (EEW) typically involves (1) detecting earthquakes in the early stages of fault rupture; (2) rapidly predicting the intensity of the impending shaking at selected target sites (or across regions); and (3) issuing alerts to end users that trigger important risk-mitigation actions before the arrival of the potentially damaging seismic motions (Allen and Melgar 2019). Depending on source-to-site distance (Wald 2020), EEW systems can provide up to a few tens of seconds of warning time. Examples of mitigating actions facilitated by EEW include the "drop, cover, and hold-on" manoeuvre (for avoiding injuries), the stopping of elevators at the nearest floor, the opening of firehouse doors, the slowing of high-speed trains, and the saving of vital computer information (e.g., Porter 2020).

We particularly focus on regional EEW systems in this study. These systems generally carry out step (2) of EEW by leveraging information provided in the early portion of near-fault seismic signals (e.g., 3-4 s of P- and/or S-waves) to determine source parameter estimates, which are used to predict resulting ground-motion intensity measures (IMs) at distant sites (e.g., Cremen and Galasso 2020). The uncertainty of this process may be captured by applying the well-known probabilistic seismic hazard analysis (PSHA; Cornell 1968) framework in real-time (i.e., RTPSHA; e.g., Iervolino et al. 2006; Convertito et al. 2008), as follows:

$$
f_{I M}(\mathbf{i m} \mid \mathbf{d})=\int_{m} \int_{r} f(\mathbf{i m} \mid m, r) f_{M}(m \mid \mathbf{d}) f_{R}(r \mid \mathbf{d}) d m d r
$$

where $f_{A}(a \mid b)$ is the probability density function of $a$ conditional on $b$, $\mathbf{d}$ are physical characteristics of the early seismic signals, $f_{M}(m \mid \mathbf{d})$ and $f_{R}(r \mid \mathbf{d})$ are respectively the realtime probability distributions of magnitude and source-to-site distance, and $f_{I M}(\mathbf{i m} \mid m, r)$ is typically computed using a ground-motion model (GMM). Equation 1 produces realtime-dependent hazard curves, which are then used to determine whether an alert should be issued to relevant end users (in step 3). For instance, a simple decisional rule consists of issuing an EEW alarm at a target site if $p\left(I M \geq I M_{c r}\right)$ is larger than a predefined threshold $\left(p_{c r}\right)$, where $I M_{c r}$ is a critical IM value for an asset of interest (Iervolino 2011).

The aforementioned strategy may lead to poor alert performance (i.e., frequent occurrences of costly false alarms and/or potentially deadly missed alarms) for structural applications, since the shaking (i.e., engineering demand) experienced in mid- to high-rise buildings is generally significantly different from that on the ground (e.g., Shome et al. 1998). To address this challenge, Cremen and Galasso (2021) recently proposed an engineering-oriented decision-making methodology for building-level EEW. This methodology leverages the performance-based earthquake early warning framework developed by Iervolino (2011) and explicitly uses risk-based predictions to determine whether an EEW alert should be triggered. However, the advanced earthquake-engineering assessment procedure adopted in the methodology requires a significant amount of structure-specific information, which makes the Cremen and Galasso (2021) approach unsuitable for application to large numbers of buildings in a region.

To facilitate more informed EEW decision-making for the latter case (i.e., building portfolios), this study employs simplified building models that can be used to approximate structural responses due to dynamic loadings (e.g., Hoenderkamp and Snijder 2000; Iwan 1997; Saiidi and Sozen 1981; Vukobratović and Fajfar 2016; Miranda and Taghavi 2005; Miranda and Akkar 2006). We specifically develop empirical equations 
that directly relate earthquake source and site information $(M, R$, and soil type) to estimates of Interstory Drift Ratio (IDR) and Peak Floor Acceleration (PFA) engineering demand parameters (EDPs) for a wide range of structures. Based on these equations, Eq. 1 can be modified to:

$$
f_{E D P}(\mathbf{e d p} \mid \mathbf{d})=\int_{m} \int_{r} f_{E D P}(\mathbf{e d p} \mid m, r) f_{M}(m \mid \mathbf{d}) f_{R}(r \mid \mathbf{d}) d m d r
$$

where $f_{E D P}(\mathbf{e d p} \mid m, r)$ is the joint PDF of the estimated EDP conditional on M and R.

It is important to note that $f_{E D P}(\mathbf{e d p} \mid \mathbf{d})$ could also be obtained using probabilistic seismic demand analysis (PSDA; e.g., Shome et al. 1998), in which RTPSHA would be coupled with a probabilistic seismic demand model (PSDM). PSDMs relate EDP(s) and selected ground-motion IM(s) based on nonlinear analysis of structural response using ground-motion records (e.g., Jalayer and Cornell 2009), from which $f_{E D P}(\mathbf{e d p} \mid \mathbf{i m})$ can be determined via statistical inference methods (e.g., linear regression). However, the introduction of $f_{E D P}(\mathbf{e d p} \mid \mathbf{i m})$ would require an IM integral in addition to those of Eq. 2, making PSDA a less efficient/suitable approach for the real-time (EEW) applications of interest in this study.

This paper is organized as follows. We first develop the empirical EDP prediction model, leveraging well-established methodologies for approximating seismic responses in multistory buildings. We next implement the EDP model in the real-time framework of Eq. 2, to demonstrate its application to EEW. We finally demonstrate the improved EEW alert accuracy obtained by triggering alarms based on EDPs instead of IMs.

\section{Developing the empirical EDP prediction model}

\subsection{Quantifying approximate seismic responses}

We quantify the approximate elastic seismic responses of multistory buildings, using the simplified structural model presented in Miranda (1999), which has been widely applied in the literature (e.g., Galasso et al. 2013; Cheng et al. 2014; Neam and Taghikhany 2016; De Bortoli and Zareian 2018). This continuous model with uniform mass and lateral stiffness distribution comprises one flexural and one shear cantilever beam, which are connected by an infinite number of axially rigid link members that transmit horizontal forces. The base is assumed to be fixed, such that foundation flexibility is neglected and torsional deformations are ignored. While the assumption of constant mass along the height is reasonable for most structures, the assumption of consistent lateral stiffness is only valid for low-rise buildings (e.g., less than three stories). However, Miranda and Taghavi (2005) concluded that the dynamic characteristics of a uniform model sufficiently approximate those of non-uniform models in many cases.

The Miranda (1999) model requires three building-specific parameters $-T_{1}, \xi_{i}$, and $\alpha$ - to compute approximate demands for a given ground motion (i.e., mode shapes, modal participation factors, and the ratio of the period of vibration of higher modes to the fundamental period are fully defined by only three parameters). $T_{1}$ is the first mode period of vibration and $\xi_{i}$ is the damping ratio of the $i$ th mode. $\alpha$ regulates the relative participation of shear and flexural deformations in the model, and is defined as follows: 


$$
\alpha=H \sqrt{\frac{G A}{E I}}
$$

where $G A$ is the shear rigidity of the shear beam, $E I$ is the bending stiffness of the flexural beam, and $H$ is the building height. Note that $H$ is estimated in this study from $T_{1}$, using the following relationship for generic structures provided in ASCE 7-2010 (2010):

$$
H=\sqrt[0.75]{\frac{T_{1}}{0.0488}}
$$

Figure 1 illustrates the influence of the $\alpha$ parameter on first mode characteristics.

We examine $P F A, I D R$, and maximum interstory drift ratio $(M I D R)$ EDPs in this study. $P F A$ is obtained using the methodology of Miranda and Taghavi (2005). IDR and MIDR are computed according to the procedure of Miranda and Akkar (2006). We exclusively account for the first six modes, given that their cumulative effective modal mass equates to more than $90 \%$ of the total for most real buildings (Galasso et al. 2013), and assume $\xi_{i}=$ $5 \%$ for each. To capture the responses of a wide range of structures, we consider 15 values of $T_{1}$ from $0.1 \mathrm{~s}$ to $5 \mathrm{~s}$ (in increments of 0.1 up to $0.5 \mathrm{~s}$, increments of 0.25 between 0.5 and $1 \mathrm{~s}$, and increments of 0.5 for larger periods), three values of $\alpha(0.1,8,30)$ that respectively represent shear wall buildings, dual systems, and moment-resisting frames (see Fig. 1), and 101 equally spaced values of relative height (i.e., nondimensional quantities that result from normalization by the total building height and vary from 0 to 1 ).

\subsection{Model format}

We develop empirical equations that directly relate the approximate building responses of Sect. 2.1 to earthquake source parameters that can be rapidly estimated with a regional EEW algorithm (i.e., typically magnitude and epicentral location), and site-specific soil characteristics. We use the functional form of the ground motion model (GMM) developed by Akkar and Bommer (2010), but substitute the Joyner-Boore distance metric with epicentral distance $\left(R_{e p i}\right)$, since current investigations on the practical implementation of

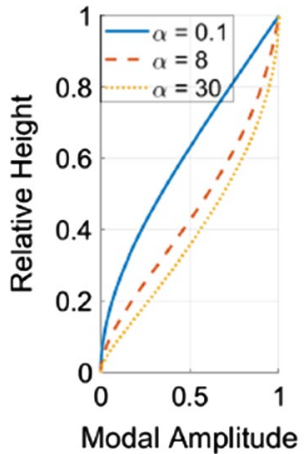

(a)

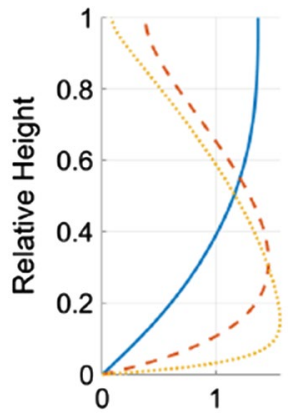

First Derivative of Modal Amplitude

(b)

Fig. 1 Variation with relative building height of $\mathbf{a}$ the amplitude of the first mode shape and $\mathbf{b}$ the first derivative of this amplitude, for three values of $\alpha$ 
European EEW are focused on point-source algorithms (Cremen et al. 2021). We also exclude the style-of-faulting indicators, given that the relevant data are not usually produced from an EEW algorithm (Minson et al. 2014). The final format of the equations to be developed is:

$$
\begin{aligned}
\log _{10} Y= & b_{1}+b_{2} M+b_{3} M^{2}+\left(b_{4}+b_{5} M\right) \log _{10} \sqrt{R_{e p i}^{2}+b_{6}^{2}}+b_{7} S_{s} \\
& +b_{8} S_{a}+\mathcal{N}(0, \tau)+\mathcal{N}(0, \phi)
\end{aligned}
$$

where, for a prescribed value of $\alpha$ and $T_{1}$ (and conditional on $\xi_{i}=5 \%$ for all modes), $Y$ is the EDP of interest (i.e., $P F A$ at a given floor height, $I D R$ for a given story height, or $M I D R)$, taken as the geometric mean of the values computed for the two horizontal components of a ground motion. $M$ is moment magnitude. $S_{s}$ and $S_{a}$ are 0 except in the case of soft-soil $\left(S_{s}=1\right)$ or stiff-soil $\left(S_{a}=1\right)$ sites. $\mathcal{N}(\mu, \Sigma)$ is a normal distribution with mean $\mu$ and standard deviation $\Sigma, \tau$ is the inter-event standard deviation, $\phi$ is the intra-event standard deviation, and $\sigma=\sqrt{\tau^{2}+\phi^{2}}$ is the total standard deviation.

\subsection{Model calibration}

We calibrate the model using a subset of the ITACA v1.0 Italian strong-motion database (Pacor et al. 2011), which contains 3955 three-component processed accelerograms from approximately $1800 M_{w} \leq 6.9$ seismic events that occurred in Italy during the period 19722009. We select this database, given that its complete set of ground-motion records is rapidly accessible via the REXEL 3.5 software tool (Iervolino et al. 2010), whereas newer and/or alternative databases require tedious record-by-record downloading or impose strict time-based limits on data accessibility. We specifically consider records with $R_{\text {epi }} \leq 200$ $\mathrm{km}$ from $M_{w} \geq 5$ events for which the faulting style is known. This results in a final dataset of 580 two-component records from 54 seismic events (see Fig. 2). $74 \%$ of the considered records are from normal faulting earthquakes, $20 \%$ are from reverse faulting earthquakes,

Fig. 2 A summary of the records used to develop the empirical models, with respect to magnitude and epicentral distance
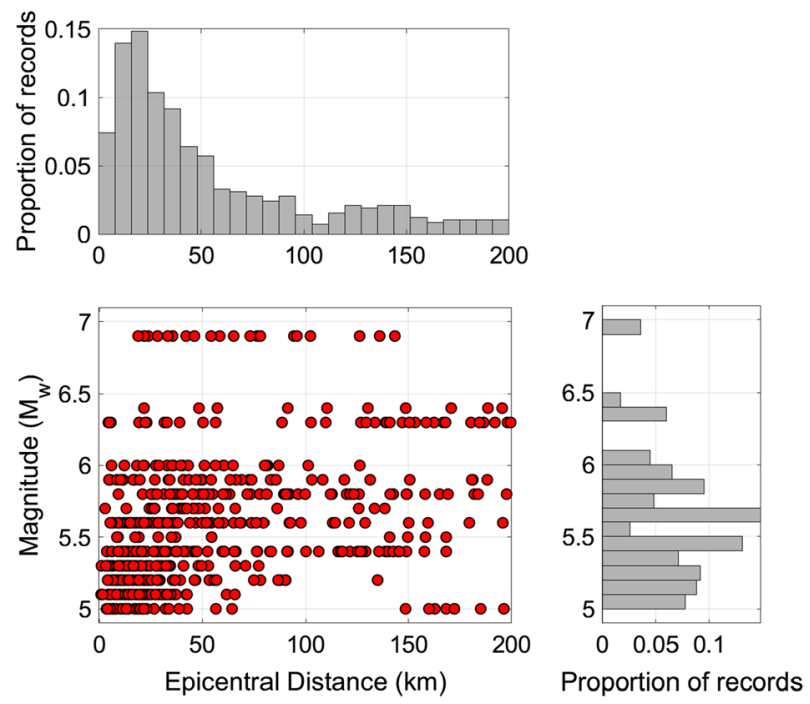
and $6 \%$ are from strike-slip events. $46 \%$ of the examined accelerograms were recorded on rock, $29 \%$ were recorded on stiff soil, and $25 \%$ were recorded on soft soil $\left(V_{s 30}<360 \mathrm{~m} / \mathrm{s}\right)$.

We calculate the coefficients of Eq. 5 for each set of $\left\{T_{1}, \alpha, h, \xi_{i}=5 \%\right\}$ as follows. We first determine a preliminary set of $\left\{b_{k}\right\}$, using non-linear regression. We then obtain the resulting residuals, $\log _{10}\left(Z_{p, q}\right)$, according to:

$$
\begin{aligned}
\log _{10}\left(Z_{p, q}\right)= & \log _{10}\left(e d p_{o b s, p, q}\right)-\left(b_{1}+b_{2} M_{p}+b_{3} M_{p}^{2}\right. \\
& +\left(b_{4}+b_{5} M_{p}\right) \log _{10} \sqrt{R_{e p i_{p, q}}^{2}+b_{6}^{2}}+b_{7} S_{s} \\
& \left.+b_{8} S_{a}\right)
\end{aligned}
$$

$\log _{10}\left(e d p_{o b s, p, q}\right)$ is the logarithm of the geometric mean observed EDP of interest for the horizontal components of the $q$ th recording from the $p$ th event, and $M_{p}$ and $R_{e p i_{p, q}}$ are the corresponding observed magnitude and epicentral distance. All other variables are as defined in Eq. 5. We finally perform an iterative mixed-effects regression of $\log _{10}\left(Z_{p, q}\right)$ according to the algorithm of Abrahamson and Youngs (1992), to determine maximum likelihood estimates of $\tau, \phi$, and $\left\{b_{k}\right\}$. The parameters for each developed equation are provided in an electronic supplement.

\subsection{Model evaluation}

We first evaluate the distance-scaling of the developed equations. We specifically examine the variation of intra-event residuals $\left(\epsilon_{p, q}\right)$ versus epicentral distance (Scasserra et al. 2009), given that consistency in this relationship would suggest a bias in the distance attenuation. Figure 3 provides the resulting plots for a hypothetical mid-rise building $\left(T_{1}=0.75 \mathrm{~s}\right)$ and all considered values of $\alpha$. It may be observed that there is no notable distance-dependence of the residuals, indicating that the distance-scaling of the developed equations is adequate for the presented cases. We quantitatively determine the presence of a trend in intra-event residuals versus distance for each developed equation, by using linear regression to fit:

$$
\epsilon_{p, q}=a_{R}+c_{R} R_{e p i_{p, q}}+\kappa_{R_{p, q}}
$$

and testing the null hypothesis that the slope $c_{R}$ equals zero. (Note that $\epsilon_{p, q}$ corresponds to the EDP of interest, $a_{R}$ is a constant, $\kappa_{R_{p, q}}$ are residuals, and all other variables have been defined previously.) We find large $p$-values (i.e., $\geq 0.05$ ) across all of the calibrated equations, implying that the aforementioned null hypothesis cannot be rejected and therefore that there is not a statistically significant relationship between the intra-event residuals and distance in any case.

We evaluate the magnitude-scaling of the developed equations, by examining the variation of inter-event residuals $\left(\eta_{p}\right)$ versus magnitude (Scasserra et al. 2009); see Fig. 4, which uses the same hypothetical structure as Fig. 3. There is no discernible magnitude-dependent trend in the plotted residuals, suggesting that the magnitude-scaling of the developed equations is appropriate for the highlighted cases. We quantitatively define this trend for all calibrated equations, by performing a linear regression according to:

$$
\eta_{p}=a_{M}+c_{M} M_{p}+\kappa_{M_{p}}
$$

and testing the null hypothesis that $c_{M}$ is zero. ( $\eta_{p}$ corresponds to the EDP of interest, $a_{M}$ is a constant, $\kappa_{M_{p}}$ are residuals, and all other variables are as defined previously.) We find 


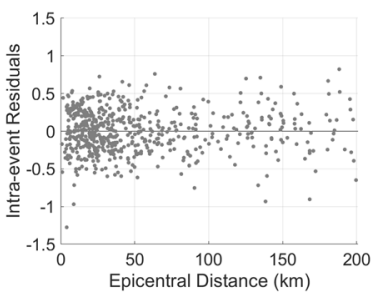

(a)

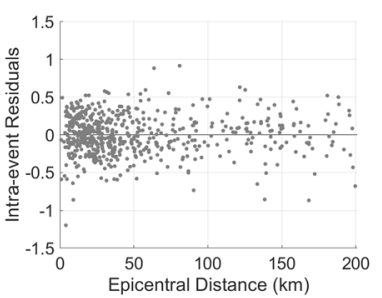

(d)

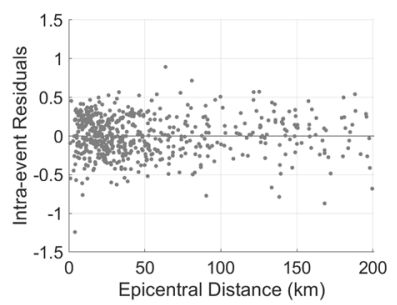

(g)

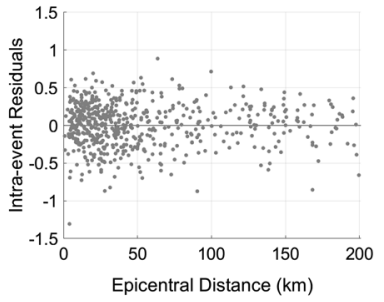

(b)

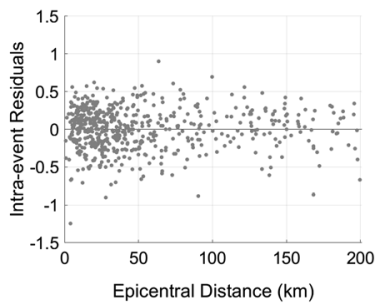

(e)

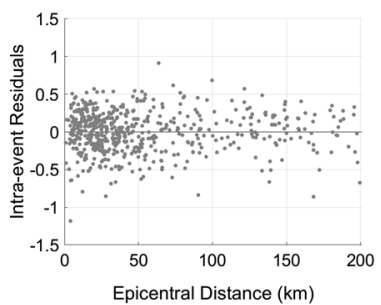

(h)

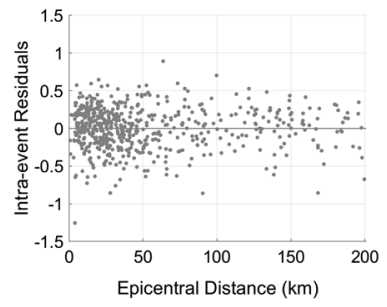

(c)

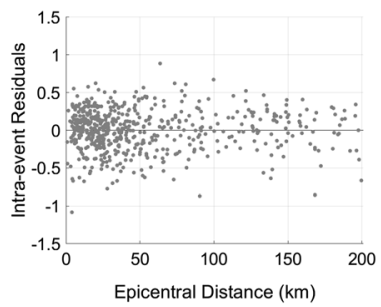

(f)

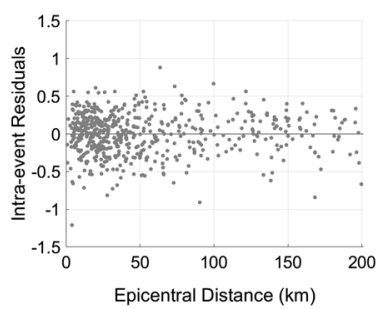

(i)

Fig. 3 Intra-event residuals versus distance for a hypothetical mid-rise building $\left(T_{1}=0.75 \mathrm{~s}\right)$ with a-c $\alpha=0.1, \mathbf{d}-\mathbf{f} \alpha=8$, and $\mathbf{g}-\mathbf{i} \alpha=30$. a, d, $\mathbf{g}$ correspond to mid-height PFA estimates, $\mathbf{b}, \mathbf{e}, \mathbf{h}$ correspond to mid-height $I D R$ estimates, and $\mathbf{c}, \mathbf{f}, \mathbf{i}$ correspond to MIDR estimates

large (i.e., $\geq 0.05)$ p-values in all cases, indicating that the null hypothesis cannot be rejected and therefore that the developed equations are adequately capturing the magnitude scaling of the observed data.

Our final evaluation focuses on the equations' $\sigma$ values. To determine whether these values are reasonable, we compare them with those of the Bindi et al. (2009) GMM (epicentral distance version). This GMM is a suitable benchmark that should be associated with comparable $\sigma$ values to those of the developed equations, since it was calibrated using many of the same earthquake recordings and contains similar predictor variables. The results of the comparison are provided in Fig. 5. It can be seen that the $\sigma$ values of both sets of equations are of the same order, and have near equivalent levels of variation (the standard deviations of the EDP and Bindi $\sigma$ values are 0.018 and 0.014 respectively). These observations confirm the acceptability of the obtained $\sigma$ values.

Based on the above evaluations, we ultimately conclude that the equations are a satisfactory fit to the underlying EDP and source data. Figures 6, 7, 8 demonstrate the close alignment between equation predictions and corresponding observed data, using 


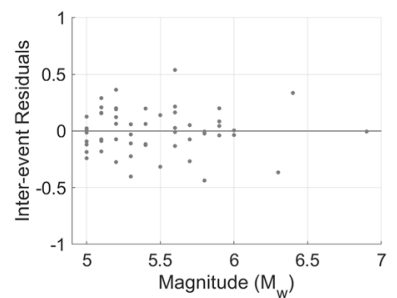

(a)

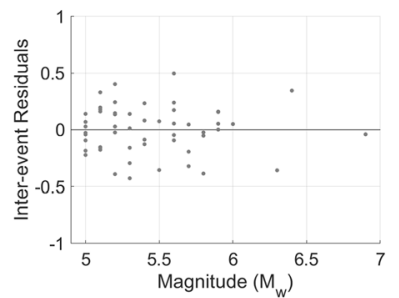

(d)

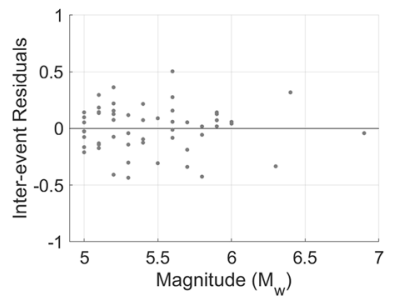

(g)

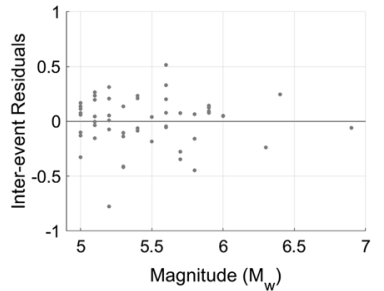

(b)

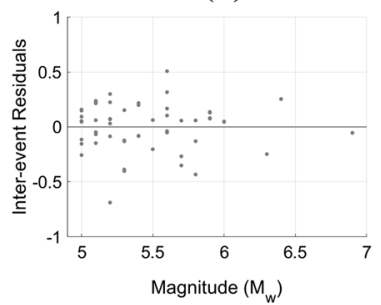

(e)

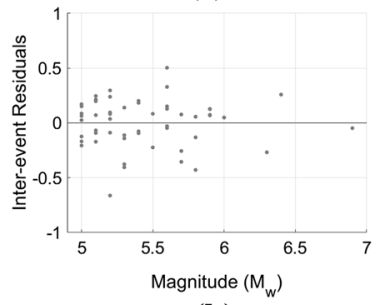

(h)

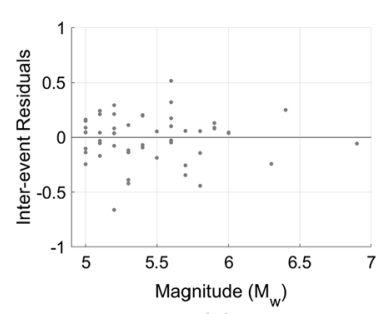

(c)

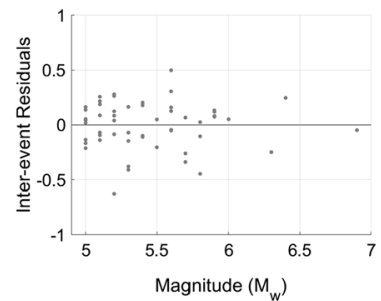

(f)

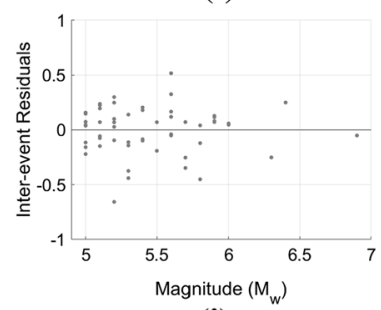

(i)

Fig. 4 Inter-event residuals versus magnitude for a hypothetical mid-rise building $\left(T_{1}=0.75 \mathrm{~s}\right)$ with a-c $\alpha=0.1, \mathbf{d}-\mathbf{f} \alpha=8$, and (g-i) $\alpha=30$. a, d, $\mathbf{g}$ correspond to mid-height PFA estimates, $\mathbf{b}, \mathbf{e}, \mathbf{h}$ correspond to mid-height $I D R$ estimates, and $\mathbf{c}, \mathbf{f}, \mathbf{i}$ correspond to $M I D R$ estimates

Fig. 5 Comparing the $\sigma$ values obtained for the empirical models developed in this study with those of the Bindi et al. (2009) GMM

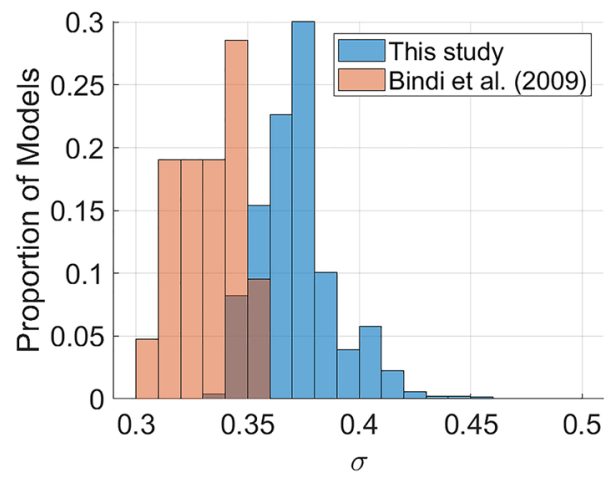

$M_{w} 6$ events, all considered soil conditions, and the hypothetical structure leveraged for Figs. 3 and 4. Note that $\alpha$ appears to have a minimal impact on predicted amplitudes for the examined $T_{1}$. For example, $M I D R$ on a rock site at $R_{e p i}=10 \mathrm{~km}$ is only $7 \%$ larger for $\alpha=30$ than for $\alpha=0.1$. However, $\alpha$ plays a more significant role at other building 


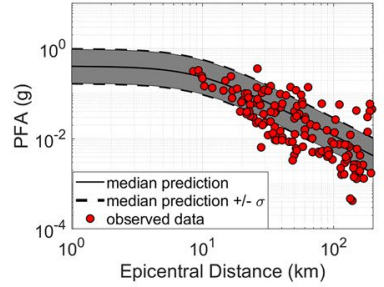

(a)

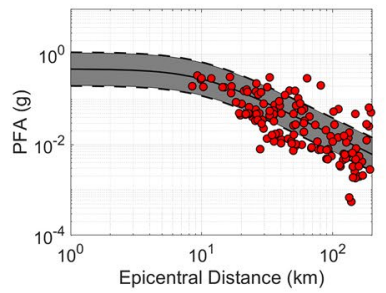

(d)

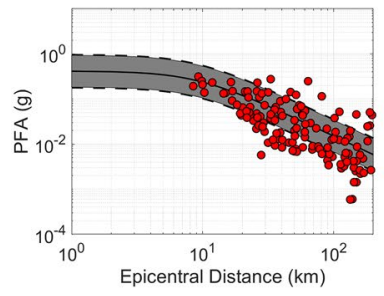

(g)

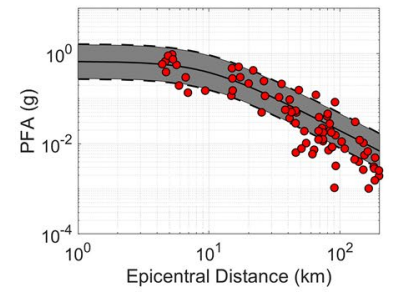

(b)

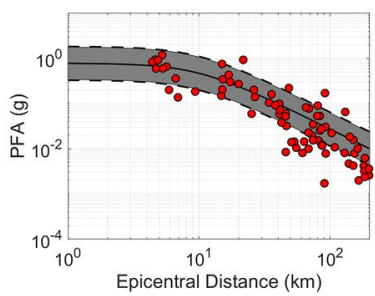

(e)

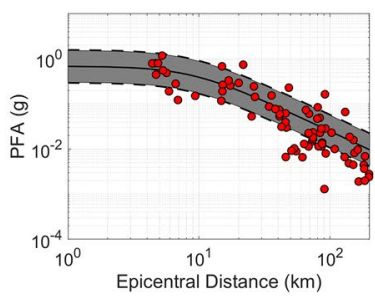

(h)

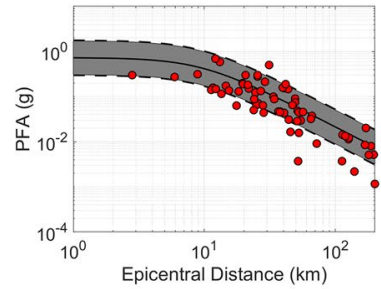

(c)

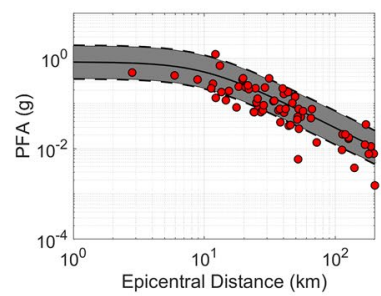

(f)

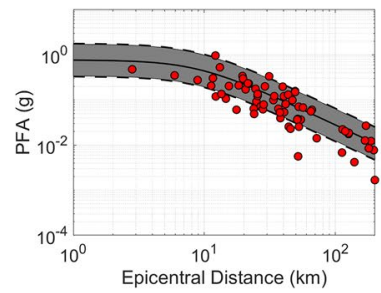

(i)

Fig. 6 Comparing mid-height $P F A$ predictions from the empirical model (for $M_{w}=6$ ) with corresponding observations (calculated from $M_{w} 5.5$ to 6.5 events), for a hypothetical mid-rise building $\left(T_{1}=0.75 \mathrm{~s}\right)$ with $\mathbf{a}-\mathbf{c} \alpha=0.1, \mathbf{d}-\mathbf{f} \alpha=8$, and $\mathbf{g}-\mathbf{i} \alpha=30$. a, d, $\mathbf{g}, \mathbf{b}, \mathbf{e}, \mathbf{h}$, and $\mathbf{c}, \mathbf{f}, \mathbf{i}$ provide comparisons for rock, stiff, and soft soil sites, respectively

periods, e.g., $M I D R$ on a rock site at $R_{e p i}=10 \mathrm{~km}$ is $19 \%$ larger for $\alpha=30$ than for $\alpha=0.1$ when $T_{1}=2$ seconds. These observations are in broad alignment with findings of previous studies (Neam and Taghikhany 2016).

\section{Real-time applications of the models}

We now apply the developed empirical models to EEW. We use the real-time analysis framework presented in Eq. 2 and case-study earthquakes at a location in the Campania region of south-west Italy (see Iervolino et al. 2009, and Fig. 9), where an EEW system is already undergoing real-time (non-public) testing (e.g., Satriano et al. 2011; Velazquez et al. 2020).

Note that we neglect distance uncertainty in this case, given its insignificance compared to that of magnitude and ground shaking (Iervolino et al. 2009), which simplifies the Eq. 2 framework to: 


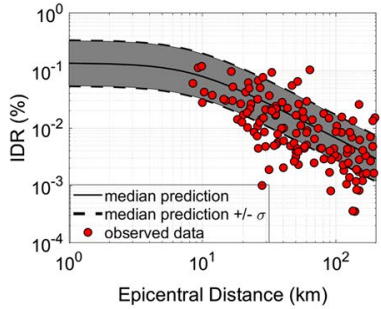

(a)

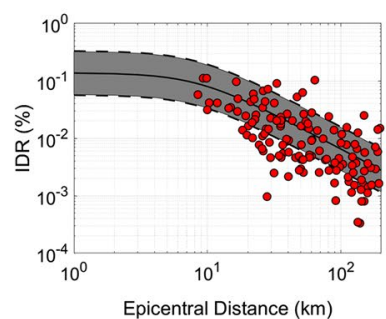

(d)

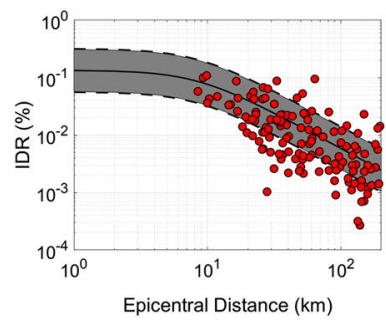

(g)

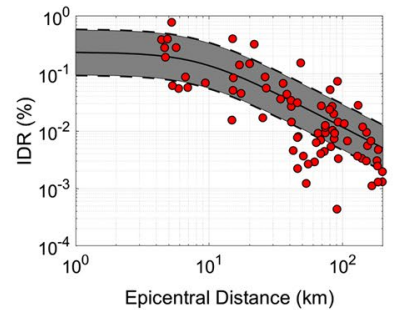

(b)

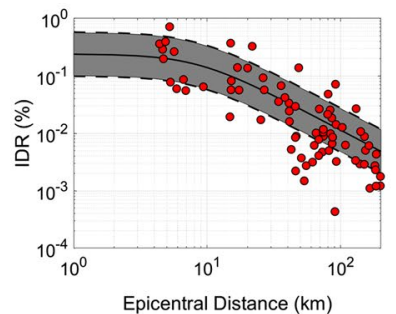

(e)

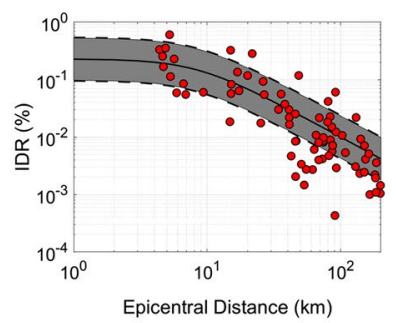

(h)

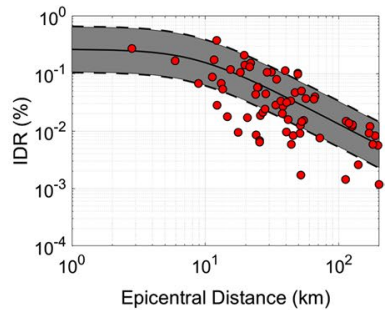

(c)

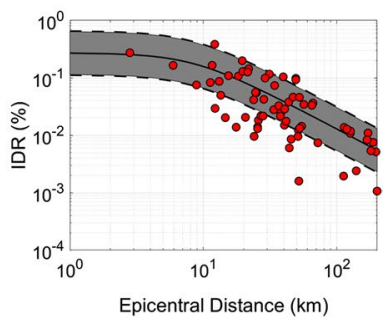

(f)

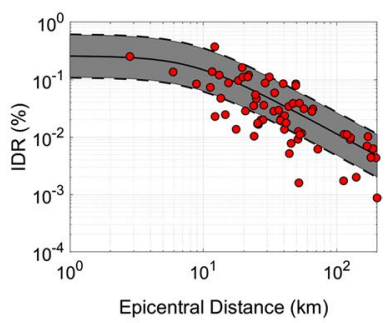

(i)

Fig. 7 Comparing mid-height $I D R$ predictions from the empirical model (for $M_{w}=6$ ) with corresponding observations (calculated from $M_{w} 5.5$ to 6.5 events), for a hypothetical mid-rise building $\left(T_{1}=0.75 \mathrm{~s}\right)$ with $\mathbf{a}-\mathbf{c} \alpha=0.1, \mathbf{d}-\mathbf{f} \alpha=8$, and $\mathbf{g - i} \alpha=30$. a, $\mathbf{d}, \mathbf{g}, \mathbf{b}, \mathbf{e}, \mathbf{h}$, and $\mathbf{c}, \mathbf{f}, \mathbf{i}$ provide comparisons for rock, stiff, and soft soil sites, respectively

$$
f_{E D P}(\mathbf{e d p} \mid \mathbf{d})=\int_{m} f_{E D P}\left(\mathbf{e d p} \mid m, R_{e p i_{t}}\right) f_{M}(m \mid \mathbf{d}) d m
$$

where $R_{e p i_{t}}$ is the true epicentral distance to the target site of interest. We adopt the Bayesian formulation for $f(m \mid \mathbf{d})$ provided in Iervolino et al. (2009), i.e.,:

$$
f(m \mid \mathbf{d})=f\left(m \mid \tau_{1}, \tau_{2}, \ldots \tau_{n}\right)=\frac{e^{\left(\frac{2 \mu_{\ln (\tau)} \sum_{i=1}^{n} \ln \left(\tau_{i}\right)-n \mu_{\ln }^{2}(\tau)}{2 \sigma_{\ln }^{2}(\tau)}\right)} e^{-\beta m}}{\int_{M_{\min }}^{M_{\max }} e^{\left(\frac{2 \mu_{\ln (\tau)} \sum_{i=1}^{n} \ln \left(\tau_{i}\right)-n \mu_{\ln }^{2}(\tau)}{2 \sigma_{\ln (\tau)}^{2}}\right)} e^{-\beta m} d m}
$$

where $\tau_{k}$ is the maximum predominant period measured within four seconds of the $\mathrm{P}$-wave arrival at the $k$ th seismic station, $n$ is the total number of seismic stations for which $\tau_{k}$ has been recorded at a given time from the event, $M_{\min }$ is the minimum considered magnitude, $M_{\max }$ is the maximum magnitude, $\beta=b / \log _{10}(e)$, and $b$ is the slope 


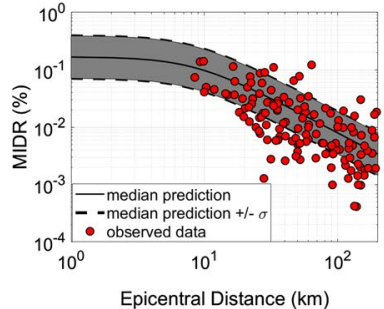

(a)

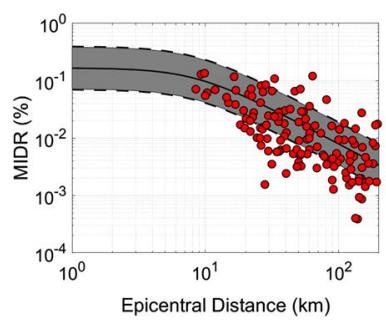

(d)

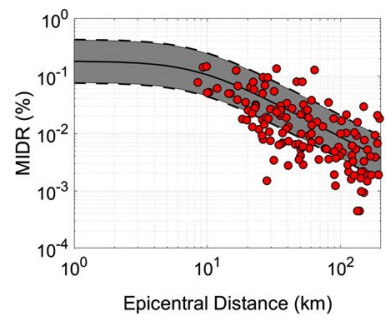

(g)

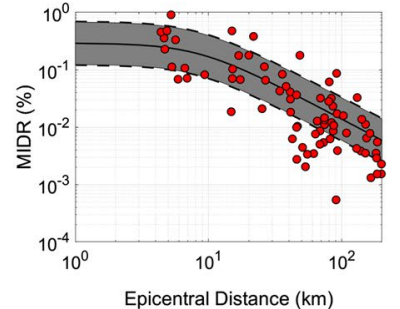

(b)

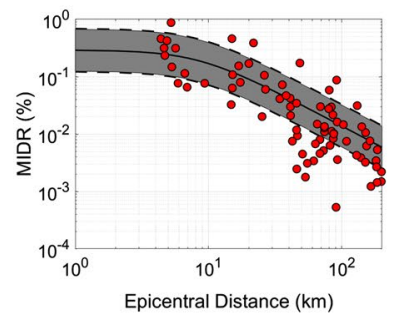

(e)

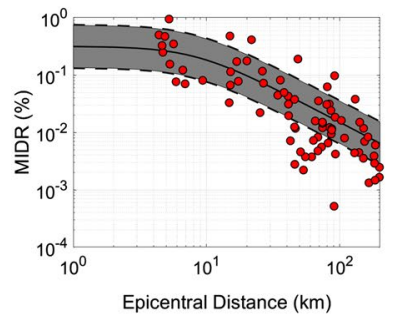

(h)

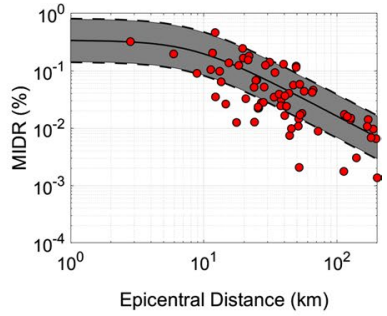

(c)

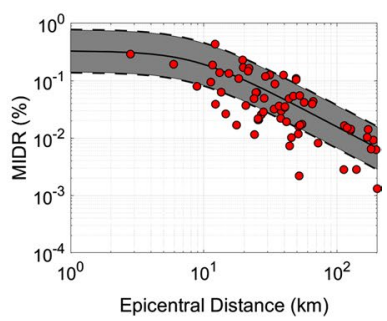

(f)

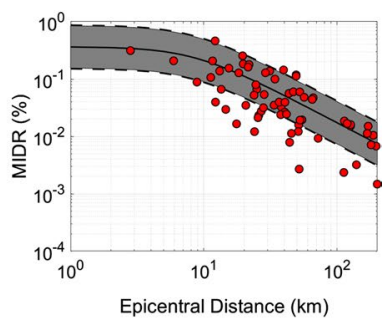

(i)

Fig. 8 Comparing $M I D R$ predictions from the empirical model (for $M_{w}=6$ ) with corresponding observations (calculated from $M_{w} 5.5$ to 6.5 events), for a hypothetical mid-rise building $\left(T_{1}=0.75 \mathrm{~s}\right)$ with a-c $\alpha=0.1, \mathbf{d}-\mathbf{f} \alpha=8$, and $\mathbf{g}-\mathbf{i} \alpha=30$. a, $\mathbf{d}, \mathbf{g}, \mathbf{b}, \mathbf{e}, \mathbf{h}$, and $\mathbf{c}, \mathbf{f}, \mathbf{i}$ provide comparisons for rock, stiff, and soft soil sites, respectively

Fig. 9 Map of the Campania region considered in the casestudy EEW application of the developed empirical models

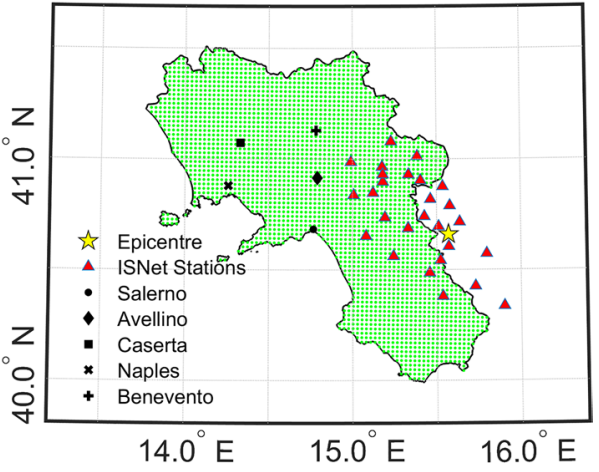


of the Gutenberg-Richter magnitude-frequency relation. $\mu_{\ln (\tau)}=(M-5.9) / 7 \log _{10}(e)$ and $\sigma_{\ln (\tau)}=0.16 / \log _{10}(e)$, based on the empirical relations of Allen and Kanamori (2003). Our analyses assume $M_{\min }=4, M_{\max }=7$, and $\beta=1.69$, in line with Iervolino et al. (2009). We leverage the Irpinia Seismic Network (ISNet) of 27 stations (Fig. 9), which is the same array used to test EEW in the region.

We first examine a target site in Naples (where $R_{\text {epit }}=124 \mathrm{~km}$ ) and focus on the evolution of EDP estimates as an increasing number of ISNet stations record $\tau_{i}$ from an incoming $M_{w} 6.9$ event. $\tau_{i}$ values are assumed to be independent and identically distributed lognormal random variables (in line with Iervolino et al. 2006), and are therefore simulated according to:

$$
f\left(\tau_{i} \mid M_{t}\right)=\frac{1}{\sqrt{2 \pi} \sigma_{\ln (\tau)} \tau_{i}} e^{-\frac{1}{2}\left(\frac{\ln \left(\tau_{i}\right)-\mu_{\ln (\tau)}}{\sigma_{\ln (\tau)}}\right)^{2}}
$$

where $M_{t}$ is the true event magnitude $(=6.9)$ and all other variables are as defined previously. These simulated values are then used to calculate $f_{E D P}(\mathbf{e d p} \mid \mathbf{d})$, according to Eq. 9 . We assume the structure of interest has $T_{1}=3 \mathrm{~s}$, to reflect the high-rise buildings located in the newly developed business area of the city, and consider all $\alpha$ values for which the models were developed. These kinds of calculations can be leveraged for building-specific EEW applications, such as early warning of floor-shaking experienced by occupants and elevator control (Cheng et al. 2014).

Figure 10 provide estimates of PFA (top floor), IDR (top story), and MIDR, averaged over 100 simulated sets of $\tau_{i}$ for different values of $n$, as well as the distributions obtained if $M_{t}$ is directly input to the relevant empirical model. Also shown is the time required to process information from each set of $n$ triggered stations $\left(t_{p_{n}}\right)$, which is calculated as follows:

$$
t_{p_{n}}=\frac{\sqrt{R_{e p i_{n}}+d^{2}}}{V_{p}}+\Delta_{t}
$$

where $R_{e p i_{n}}$ is the maximum epicentral distance associated with all $n$ triggered stations, $d$ is the hypocentral depth of the earthquake (assumed $=12 \mathrm{~km}), \Delta_{t}$ is the processing time $(=5$ $\mathrm{s}$, from Iervolino et al. 2009), and $V_{p}$ is P-wave velocity. $V_{p}$ is taken to be $5.88 \mathrm{~km} / \mathrm{s}$, based on the S-wave velocity $\left(V_{s}\right)$ of $3.5 \mathrm{~km} / \mathrm{s}$ provided for the same region in Iervolino et al. (2006) and the $\frac{V_{p}}{V_{s}}$ ratio of 1.68 used for the same earthquake location in Iervolino et al. (2009). It is observed that the predictions of Eq. 9 improve as more triggered stations contribute data to the calculations, since this increases the accuracy of $f_{M}(m \mid \mathbf{d})$ (Iervolino et al. 2006; see Fig. 14a). It is also seen that reasonably accurate EDP estimates are obtained for $n=18$ (i.e., within 12 seconds) in all cases. This result is consistent with the findings of Iervolino et al. (2009) for PGA estimates at the same target site, who used the same EEW algorithm and an $M_{w} 6$ event at the examined epicentral location.

Our second case study involves a region-wide real-time application of the proposed empirical models. We specifically examine the spatial distribution of median EDP estimates for $M_{t}=6$ and a hypothetical mid-rise building $\left(T_{1}=0.75 \mathrm{~s}, \alpha=8\right)$, using one set of simulated $\tau_{i}$ values (from Eq. 11) for various $n$. Figures 11, 12, 13 respectively provide these estimates for PFA, IDR, and MIDR, as well as the corresponding median values calculated for the true magnitude. It can be seen that early real-time calculations significantly underestimate median EDP values (particularly at close-source distances). This may be explained by the fact that for low values of $n, f(m \mid \mathbf{d})$ is dominated by its Gutenberg-Richter 


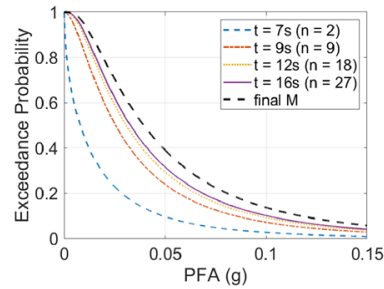

(a)

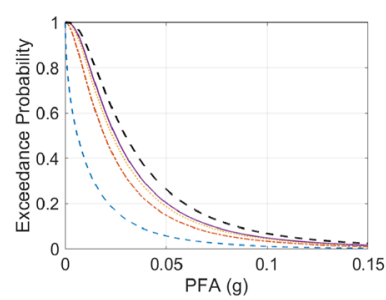

(d)

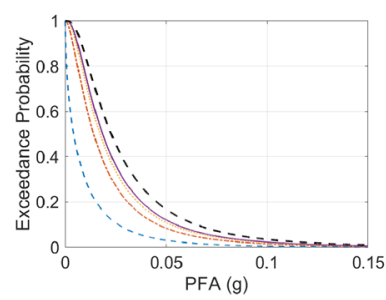

(g)

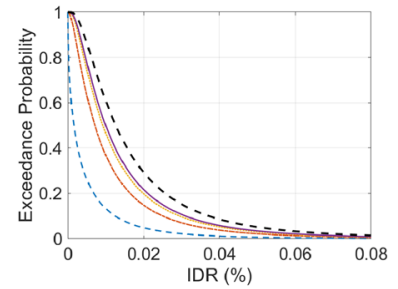

(b)

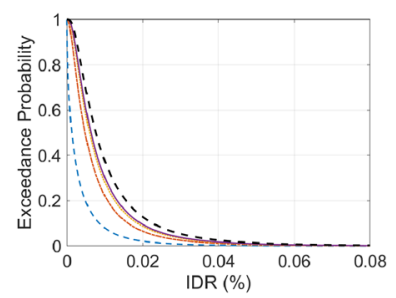

(e)

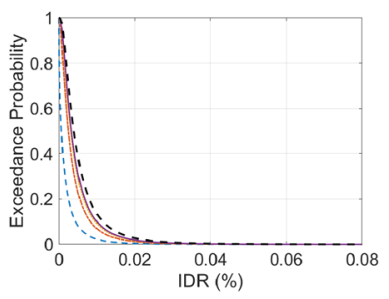

(h)

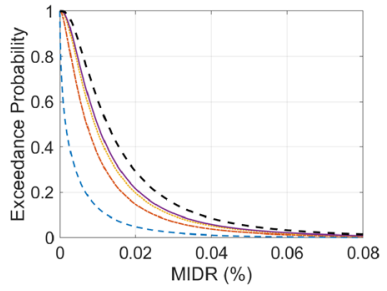

(c)

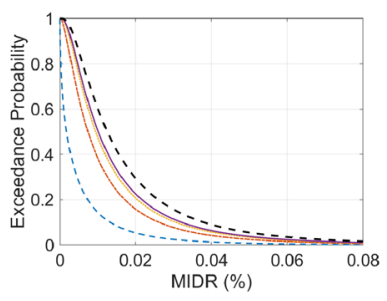

(f)

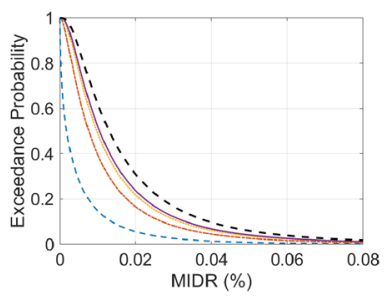

(i)

Fig. 10 Real-time evolving estimates of a, d, $\mathbf{g} P F A$ (top floor), b, e, $\mathbf{h} I D R$ (top story) and $\mathbf{c}, \mathbf{f}, \mathbf{i} M I D R$ for a hypothetical high-rise building $\left(T_{1}=3 \mathrm{~s}\right)$ at the chosen target site, compared with those obtained using the true (i.e., final) value of magnitude $\left(M_{w}=6.9\right)$, for $\mathbf{a}-\mathbf{c} \alpha=0.1, \mathbf{d}-\mathbf{f} \alpha=8$, and $\mathbf{g}-\mathbf{i} \alpha=30$

prior component (per Eq. 10), which provides an expected magnitude value that is significantly smaller than $M_{t}$ in this case (Iervolino et al. 2006; see Fig. 14b). Sufficiently accurate estimates are obtained in most of the region for approximately 18 triggered stations, across all EDPs. Evolutionary regional mapping of projected EDP estimates may be helpful for better informing the early stages of emergency response strategies that significantly depend on the functionality of target assets within the urban system (i.e., critical infrastructure).

\section{Demonstrating the benefits of EDP-based EEW trigger thresholds for buildings}

We now provide a simple demonstration of the improvement in alert accuracy offered by making decisions to trigger EEW alarms based on EDP instead of IM. We use a hypothetical mid-rise building ( $\left.T_{1}=1 \mathrm{~s}, \alpha=30\right)$, and assume that an EEW alert should be issued if the PFA caused by the impending earthquake at the top, middle or bottom floor will 


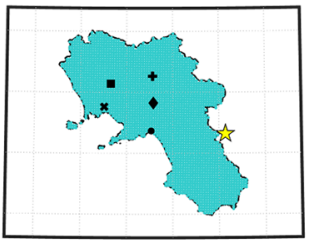

(a)

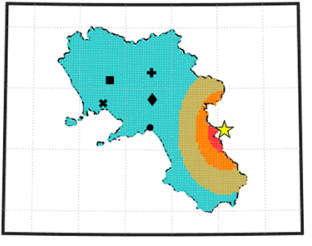

(c)

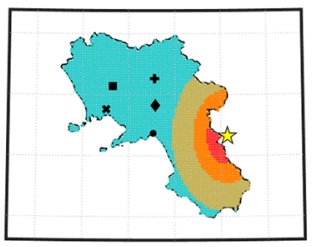

(e)

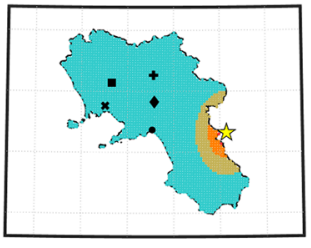

- $\operatorname{IDR}(\%)<0.005$

$0.005<\operatorname{IDR}(\%)<0.01$

$0.01<\operatorname{IDR}(\%)<0.02$

- $\operatorname{IDR}(\%)>0.02$

is Epicentre

- Salerno

- Avellino

- Caserta

* Naples

+ Benevento

(b)

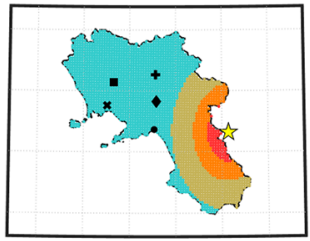

- $\operatorname{IDR}(\%)<0.005$

$0.005<$ IDR $(\%)<0.01$

$0.01<\operatorname{IDR}(\%)<0.02$

- $\operatorname{IDR}(\%)>0.02$

¿s Epicentre

- Salerno

- Avellino

- Caserta

* Naples

+ Benevento

IDR $(\%)<0.005$

- $0.005<\operatorname{IDR}(\%)<0.01$

- $0.01<\operatorname{IDR}(\%)<0.02$

- $\operatorname{IDR}(\%)>0.02$

次 Epicentre

- Salerno

- Avellino

- Caserta

× Naples

+ Benevento

(d)

Fig. 12 Region-wide estimates of IDR (top story) for a hypothetical mid-rise building $\left(T_{1}=0.75 \mathrm{~s}, \alpha=8\right.$ ) during an $M_{w} 6$ event when $\mathbf{a} n=2, \mathbf{b} n=9, \mathbf{c} n=18, \mathbf{d} n=27$, and (e) the true (i.e., final) value of magnitude is obtained

The results of these analyses are presented in Fig. 15 (for $M_{w}=6.5$, across a range of $R_{e p i}$ values) and Fig. 16 (for $R_{e p i}=60 \mathrm{~km}$, across a range of $M_{w}$ values) For both decisional rules, it is seen that false alerts can occur for low values of $R_{e p i}$ and relatively high values of $M_{w}$ (i.e., conditions under which governing median predictions are higher than $0.05 \mathrm{~g}$ ), whereas missed alerts can occur for high values of $R_{e p i}$ and relatively low values of $M_{w}$ (i.e., conditions under which governing predictions are less than $0.05 \mathrm{~g}$ ). Proportions of false and missed alerts are greatest for cases in which the corresponding governing predictions are respectively just greater than or just less than $0.05 \mathrm{~g}$. In all other cases (as intuitively expected), governing predictions and simulated $E D P \mathrm{~s}$ of interest are in better agreement with respect to this decision threshold. It can be observed that the EDP-based decisional rule provides significantly better alert accuracy than that based on IM; it reduces missed alerts by $42 \%$ for the $M_{w}=6.5$ case and by $66 \%$ for the $R_{e p i}=60 \mathrm{~km}$ case. This example underlines the notable benefit of integrating EDP predictions in building-focused applications of EEW. It is important to note that the EDP rule transforms some IM-related missed alerts into false alerts in both cases. However, these system malfunctions are generally accepted by end users (at least in regions with public EEW) as opportunities to perform unscheduled earthquake preparation exercises (Velazquez et al. 2020). 


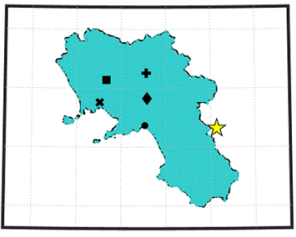

(a)

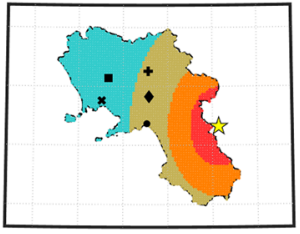

(c)

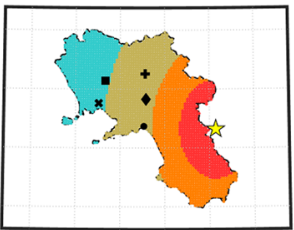

(e)

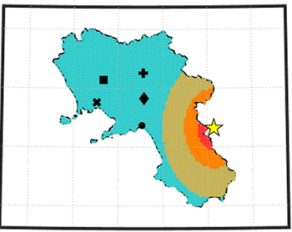

(b)

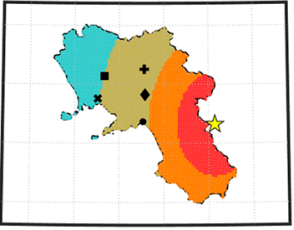

(d)

(d)
- $\operatorname{MIDR}(\%)<0.005$

$0.005<\operatorname{MIDR}(\%)<0.01$

$0.01<\operatorname{MIDR}(\%)<0.02$

- $\operatorname{MIDR}(\%)>0.02$

Epicentre

- Salerno

- Avellino

- Caserta

* Naples

+ Benevento
MIDR $(\%)<0.005$ $0.005<\operatorname{MIDR}(\%)<0.01$

- $0.01<\operatorname{MIDR}(\%)<0.02$

- $\operatorname{MIDR}(\%)>0.02$

is Epicentre

- Salerno

- Avellino

- Caserta

* Naples

+ Benevento

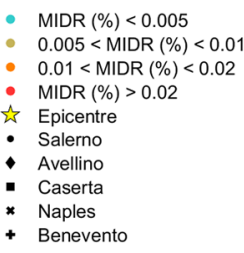

- Benevento

- $\operatorname{MIDR}(\%)<0.005$

$0.005<\operatorname{MIDR}(\%)<0.01$

$0.01<\operatorname{MIDR}(\%)<0.02$

- $\operatorname{MIDR}(\%)>0.02$

is Epicentre

- Salerno

- Avellino

- Caserta

* Naples

- Benevento

Fig. 13 Region-wide estimates of $M I D R$ for a hypothetical mid-rise building $\left(T_{1}=0.75 \mathrm{~s}, \alpha=8\right)$ during an $M_{w}$ 6 event when $\mathbf{a} n=2, \mathbf{b} n=9, \mathbf{c} n=18, \mathbf{d} n=27$, and e the true (i.e., final) value of magnitude is obtained

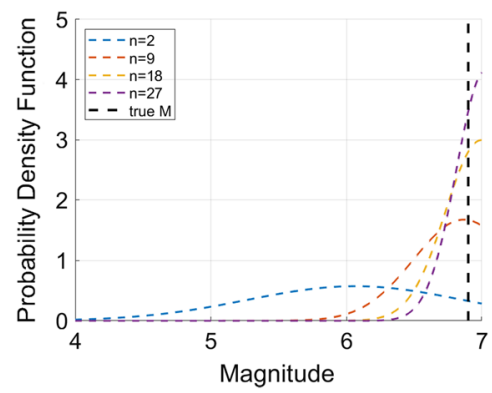

(a)

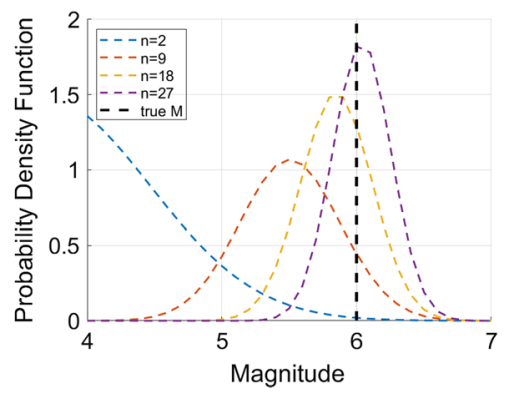

(b)

Fig. $14 f(m \mid \mathbf{d})$ for (a) an $M_{w} 6.9$ event (depicted in Fig. 10) and (b) an $M_{w} 6$ event (depicted in Figures 11, 12,13 ) when $n=2,9,18$, and 27. Also shown are the true magnitudes

Table 1 Relationship between acceleration and human comfort, adapted from Cheng et al. (2014)

\begin{tabular}{ll}
\hline Maximum acceleration $(\mathrm{g})$ & Human comfort level \\
\hline$<0.005$ & Not perceptible \\
$0.005-0.015$ & Perceptible \\
$0.015-0.05$ & Annoying \\
$>0.05$ & Very annoying \\
\hline
\end{tabular}




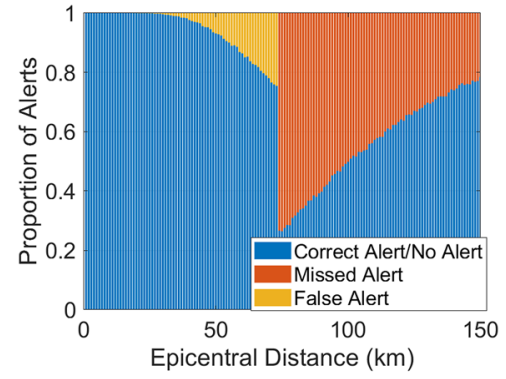

(a)

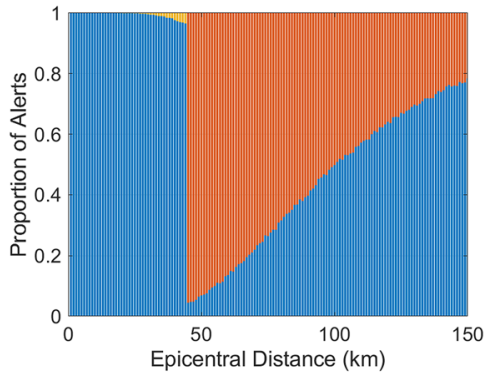

(b)

Fig. 15 Comparing the accuracy of the a PFA-based and $\mathbf{b} P G A$-based decisional rules in terms of epicentral distance, for a hypothetical mid-rise building $\left(T_{1}=1 \mathrm{~s}, \alpha=30\right)$ and $M_{w}=6.5$

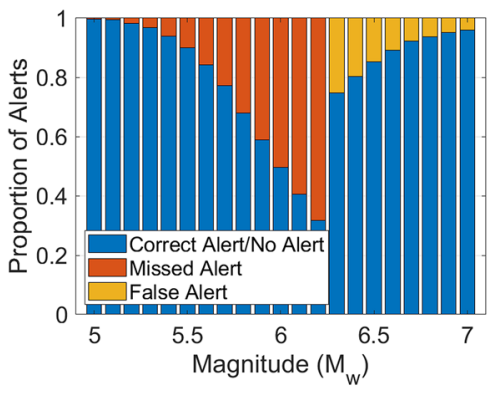

(a)

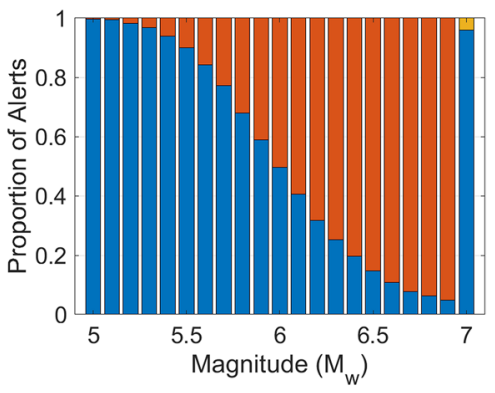

(b)

Fig. 16 Comparing the accuracy of the a $P F A$-based and $\mathbf{b} P G A$-based decisional rules in terms of magnitude, for a hypothetical mid-rise building $\left(T_{1}=1 \mathrm{~s}, \alpha=30\right)$ and $R_{e p i}=60 \mathrm{~km}$

\section{Conclusions}

This study has developed empirical EDP prediction models for use in real-time buildinglevel applications of EEW. These models directly relate approximate seismic responses of multi-story buildings (in terms of $P F A, I D R$, and MIDR) to site-specific characteristics and earthquake source parameters that can be rapidly estimated by regional EEW algorithms. We used Italian ground-motion data and well-known simplified response quantification methods (Miranda and Taghavi 2005; Miranda and Akkar 2006) to calibrate the models for three structural systems and a wide array of corresponding first mode periods.

We integrated the developed models into a real-time Bayesian framework that incorporates the evolutionary uncertainties inherent in EEW measurements. Local and regional applications of the framework for case study earthquakes in Southern Italy revealed that reasonably accurate EDP estimates could be obtained if the data from approximately 18 stations were used to estimate the magnitude of the incoming event (although these findings significantly depend on the underlying EEW algorithm employed). The EDP-based Bayesian framework may be used to design bespoke EEW alerts and determine preliminary earthquake impact estimates for targeted structures within a region. 
Finally, we quantified the improvement in EEW alert accuracy obtained if the developed models were used to determine alert thresholds instead of the IM-based prediction methods typically adopted. Using a sample structure and a hypothetical alert trigger criterion, we found that an EDP-based decisional rule could reduce the proportion of missed alerts associated with a $P G A$-driven threshold by more than $45 \%$ on average, across a series of scenario earthquakes. In summary, the results of this study facilitate a key advancement in EEW decision support, by providing an important link between the typical seismological parameters computed by EEW algorithms and their ultimate effect on the built environment.

There are some limitations associated with this study, however. Firstly, the structural model used assumes linear elastic behaviour and classical damping. This means that the empirical prediction equations are only appropriate for performance levels in which a building is expected to remain elastic or exhibit minimal nonlinear behaviour. However, nonlinear extensions of the employed structural model are available (e.g., Xu et al. 2014; Xiong et al. 2016) and could be used to derive similar prediction equations for buildingspecific EEW applications involving high-intensity ground motions. Secondly, the empirical models were determined using data from Italy only and may not be directly applicable outside this context (although the proposed methodology for model development is general and can be applied to data from any region). Thirdly, the models do not account for correlations of EDPs, either within the same structure or between closely located buildings (Sun et al. 2018). To overcome this shortcoming, (1) median model predictions could be used to quantify intra-building correlations according to the EDP correlation methodology described in Cremen and Baker (2018) and (2) inter-building EDP correlations could be quantified with model residuals, in line with procedures used for assessing spatial correlations of ground-motion intensities (e.g., Jayaram and Baker 2009; Loth and Baker 2013).

On a final note, future work will consider expanding the Eq. 2 framework to account for losses, which contain the highest level of information for decision making about alarm issuance (e.g., Iervolino et al. 2007). This effort would represent a significant step towards achieving a portfolio-level analogue of the engineering-driven EEW decision-making methodology proposed by Cremen and Galasso (2021).

Author Contributions All authors helped to conceive and design the research. G.C. drafted the written content of the manuscript, which C.G. and G.C. reviewed. G.C. performed the main calculations, using input data prepared by O.V. and B.O.

Funding This paper is supported by the European Union's Horizon 2020 research and innovation programme under grant agreement No 821046, project TURNkey (Towards more Earthquake-resilient Urban Societies through a Multi-sensor-based Information System enabling Earthquake Forecasting, Early Warning and Rapid Response actions) and the Mexican Consejo Nacional de Ciencia y Tecnología (Grant Reference: 398485$)$.

\section{Declarations}

Conflict of interest There are no conflicts of interest associated with this research.

Availability of data and material All data are available from the authors on reasonable request. Coefficients of the empirical EDP prediction model will be made available on Github at https://github.com/gcrem/Appro ximate-Seismic-Responses-for-EEW, upon acceptance of the manuscript.

Code availability Code used in this research is available from the authors on reasonable request. 
Open Access This article is licensed under a Creative Commons Attribution 4.0 International License, which permits use, sharing, adaptation, distribution and reproduction in any medium or format, as long as you give appropriate credit to the original author(s) and the source, provide a link to the Creative Commons licence, and indicate if changes were made. The images or other third party material in this article are included in the article's Creative Commons licence, unless indicated otherwise in a credit line to the material. If material is not included in the article's Creative Commons licence and your intended use is not permitted by statutory regulation or exceeds the permitted use, you will need to obtain permission directly from the copyright holder. To view a copy of this licence, visit http://creativecommons.org/licenses/by/4.0/.

\section{References}

Abrahamson NA, Youngs R (1992) A stable algorithm for regression analyses using the random effects model. Bull Seismol Soc Am 82(1):505-510

Akkar S, Bommer JJ (2010) Empirical equations for the prediction of PGA, PGV, and spectral accelerations in Europe, the Mediterranean region, and the Middle East. Seismol Res Letts 81(2):195-206

Allen RM, Kanamori H (2003) The potential for earthquake early warning in Southern California. Science 300(5620):786-789. https://doi.org/10.1126/science.1080912

Allen RM, Melgar D (2019) Earthquake early warning: advances, scientific challenges, and societal needs. Annu Rev Earth Planet Sci. https://doi.org/10.1146/annurev-earth-053018-060457

ASCE 7-2010 (2010) Minimum design loads for buildings and other structures, ASCE/SEI 7-10 edn. American Society of Civil Engineers. https://doi.org/10.1061/9780784412916

Bindi D, Luzi L, Pacor F, Sabetta F, Massa M (2009) Towards a new reference ground motion prediction equation for Italy: update of the Sabetta-Pugliese (1996). Bull Earthq Eng 7(3):591-608

Bindi D, Luzi L, Massa M, Pacor F (2010) Horizontal and vertical ground motion prediction equations derived from the Italian accelerometric archive (Itaca). Bull Earthq Eng 8(5):1209-1230

Bindi D, Pacor F, Luzi L, Puglia R, Massa M, Ameri G, Paolucci R (2011) Ground motion prediction equations derived from the Italian strong motion database. Bull Earthq Eng 9(6):1899-1920

Cheng MH, Wu S, Heaton TH, Beck JL (2014) Earthquake early warning application to buildings. Eng Struct 60:155-164

Convertito V, Iervolino I, Zollo A, Manfredi G (2008) Prediction of response spectra via real-time earthquake measurements. Soil Dyn Earthq Eng 28(6):492-505

Cornell CA (1968) Engineering seismic risk analysis. Bull Seismol Soc Am 58(5):1583-1606

Cremen G, Baker JW (2018) Quantifying the benefits of building instruments to FEMA P-58 rapid postearthquake damage and loss predictions. Eng Struct 176:243-253

Cremen G, Galasso C (2020) Earthquake early warning: recent advances and perspectives. Earth-Sci Rev 205:103184

Cremen G, Galasso C (2021) A decision-making methodology for risk-informed earthquake early warning. Comput-Aided Civ Inf in press

Cremen G, Zuccolo E, Galasso C (2021) Accuracy and uncertainty analysis of selected methodological approaches to earthquake early warning in Europe. Seismol Res Letts in press

De Bortoli M, Zareian F (2018) Performance prediction equations for linear planar structural systems: concept, formulation, and validation. Earthq Spectra 34(2):697-718

Galasso C, Zhong P, Zareian F, Iervolino I, Graves RW (2013) Validation of ground-motion simulations for historical events using MDOF systems. Earthq Eng Struct Dyn 42(9):1395-1412

Hoenderkamp J, Snijder H (2000) Approximate analysis of high-rise frames with flexible connections. Struct Design Tall Build 9(3):233-250

Iervolino I (2011) Performance-based earthquake early warning. Soil Dyn Earthq Eng 31(2):209-222. https://doi.org/10.1016/j.soildyn.2010.07.010

Iervolino I, Convertito V, Giorgio M, Manfredi G, Zollo A (2006) Real-time risk analysis for hybrid earthquake early warning systems. J Earthq Eng 10(06):867-885

Iervolino I, Giorgio M, Manfredi G (2007) Expected loss-based alarm threshold set for earthquake early warning systems. Earthq Eng Struct Dyn 36(9):1151-1168

Iervolino I, Giorgio M, Galasso C, Manfredi G (2009) Uncertainty in early warning predictions of engineering ground motion parameters: What really matters? Geophys Res Lett 36(4):L00B06. https://doi.org/ $10.1029 / 2008$ GL036644

Iervolino I, Galasso C, Cosenza E (2010) REXEL: computer aided record selection for code-based seismic structural analysis. Bull Earthq Eng 8(2):339-362 
Iwan W (1997) Drift spectrum: measure of demand for earthquake ground motions. J Struct Eng 123(4):397-404

Jalayer F, Cornell C (2009) Alternative non-linear demand estimation methods for probability-based seismic assessments. Earthq Eng Struct Dyn 38(8):951-972

Jayaram N, Baker JW (2009) Correlation model for spatially distributed ground-motion intensities. Earthq Eng Struct Dyn 38(15):1687-1708

Loth C, Baker JW (2013) A spatial cross-correlation model of spectral accelerations at multiple periods. Earthq Eng Struct Dyn 42(3):397-417

Minson SE, Murray JR, Langbein JO, Gomberg JS (2014) Real-time inversions for finite fault slip models and rupture geometry based on high-rate GPS data. J Geophys Res Solid Earth 119(4):3201-3231

Minson SE, Baltay AS, Cochran ES, Hanks TC, Page MT, McBride SK, Milner KR, Meier MA (2019) The limits of earthquake early warning accuracy and best alerting strategy. Sci Rep. https://doi.org/10. 1038/s41598-019-39384-y

Miranda E (1999) Approximate seismic lateral deformation demands in multistory buildings. J Struct Eng 125(4):417-425

Miranda E, Akkar S (2006) Generalized interstory drift spectrum. J Struct Eng 132(6):840-852

Miranda E, Taghavi S (2005) Approximate floor acceleration demands in multistory buildings. i: Formulation. J Struct Eng 131(2):203-211

Neam AS, Taghikhany T (2016) Prediction equations for generalized interstory drift spectrum considering near-fault ground motions. Nat Hazards 80(3):1443-1473

Pacor F, Paolucci R, Luzi L, Sabetta F, Spinelli A, Gorini A, Nicoletti M, Marcucci S, Filippi L, Dolce M (2011) Overview of the Italian strong motion database ITACA 1.0. Bull Earthq Eng 9(6):1723-1739

Porter K (2020) Best practices for earthquake early warning: a compendium. SPA Risk LLC, Denver, Colorado

Saiidi M, Sozen MA (1981) Simple nonlinear seismic analysis of R/C structures. J Struct Division 107(5):937-953

Satriano C, Elia L, Martino C, Lancieri M, Zollo A, Iannaccone G (2011) PRESTo, the earthquake early warning system for Southern Italy: Concepts, capabilities and future perspectives. Soil Dyn Earthq Eng 31(2):137-153. https://doi.org/10.1016/j.soildyn.2010.06.008

Scasserra G, Stewart JP, Bazzurro P, Lanzo G, Mollaioli F (2009) A comparison of NGA ground-motion prediction equations to Italian data. Bull Seismol Soc Am 99(5):2961-2978

Shome N, Cornell CA, Bazzurro P, Carballo JE (1998) Earthquakes, records, and nonlinear responses. Earthquake Spectra 14(3):469-500

Sun H, Burton H, Zhang Y, Wallace J (2018) Interbuilding interpolation of peak seismic response using spatially correlated demand parameters. Earthq Eng Struct Dyn 47(5):1148-1168

Velazquez O, Pescaroli G, Cremen G, Galasso C (2020) A review of the technical and socio-organizational components of earthquake early warning systems. Front Earth Sci 8:445

Vukobratović V, Fajfar P (2016) A method for the direct estimation of floor acceleration spectra for elastic and inelastic MDOF structures. Earthq Eng Struct Dyn 45(15):2495-2511

Wald DJ (2020) Practical limitations of earthquake early warning. Earthq Spectra 36(3):1412-1447

Xiong C, Lu X, Guan H, Xu Z (2016) A nonlinear computational model for regional seismic simulation of tall buildings. Bull Earthq Eng 14(4):1047-1069

Xu Z, Lu X, Guan H, Han B, Ren A (2014) Seismic damage simulation in urban areas based on a highfidelity structural model and a physics engine. Nat hazards 71(3):1679-1693

Publisher's Note Springer Nature remains neutral with regard to jurisdictional claims in published maps and institutional affiliations.

\section{Authors and Affiliations}

\section{Gemma Cremen $^{1}$ (D) $\cdot$ Omar Velazquez ${ }^{2} \cdot$ Benazir Orihuela $^{3} \cdot$ Carmine Galasso $^{4,5}$}

1 Department of Civil, Environmental and Geomatic Engineering, University College London, Gower Street, London, U.K.

2 Institute for Risk and Disaster Reduction, University College London, 2nd Floor, South Wing, UCL Main Quadrangle, London, U.K. 
3 Ciencias de la Tierra Solida CTS, Instituto Geofisico del Peru IGP, Calle Calatrava 216, Urb. Camino Real, La Molina, Lima, Peru

4 Department of Civil, Environmental and Geomatic Engineering, University College London, Gower Street, London, U.K.

5 Scuola Universitaria Superiore IUSS, Pavia, Italy 